\title{
Molecular cloning and expression analysis of the $G N A S$ gene in pig and porcine fibroblast cells
}

\author{
J. Peng ${ }^{1}$, Y.L. Li ${ }^{1}$, Y.F. Shen ${ }^{1}$, Y. Wang ${ }^{2}$ and N.Y. Xu' ${ }^{1}$ \\ ${ }^{1}$ College of Animal Sciences, Zhejiang University, Hangzhou, China \\ ${ }^{2}$ College of Mechanics, Taiyuan University of Technology, Taiyuan, China \\ Corresponding authors: Y. Wang / N.Y. Xu \\ E-mail: wangying03@tyut.edu.cn / nyxu@zju.edu.cn
}

Genet. Mol. Res. 13 (3): 5463-5473 (2014)

Received June 11, 2013

Accepted October 31, 2013

Published July 24, 2014

DOI http://dx.doi.org/10.4238/2014.July.24.26

\begin{abstract}
The Alpha subunit of the stimulatory guanine nucleotidebinding protein (GNAS) is a complex imprinted gene. The major product of the $G N A S$ gene is the $\alpha$-subunit of the guanine nucleotide-binding protein (Gas), which plays a key role in multiple signal transduction pathways. Gas is required for the production of the receptor-stimulated intracellular cyclic adenosine monophosphate (cAMP). It has been demonstrated that an increase in the concentration of the intracellular second messenger cAMP promotes apoptosis in different tumor entities. Mutations of GNAS have also been identified in many tumors. This study aimed to investigate the expression pattern and the apoptosis effect in fibroblast cells for porcine GNAS. The results show that GNAS mRNA was detected in a wide range of tissues, especially in the longissimus dorsi muscle and thyroid gland. The developmental pattern of GNAS mRNA in the thyroid gland of Jinhua pigs was then examined; however, there was no significant difference $(P>0.05)$ among any of the stages. GNAS gene expression was relatively stable in the thyroid gland during the entire growth and development process. The developmental pattern of GNAS mRNA in the longissimus dorsi muscle was significantly different among the various developmental stages $(\mathrm{P}<0.01)$. GNAS mRNA was strongly expressed at 60 days, 90 days, and 150 days after birth, whereas the expression level was very
\end{abstract}


low during the embryo stages. Target RNA interference of GNAS in porcine fibroblast cells leads to lower mRNA expression of Bcl-2, Fas, and Caspase-3, which are recognized as apoptosis related markers.

Key words: Apoptosis; Guanine nucleotide-binding protein; Pig; Thyroid gland

\section{INTRODUCTION}

Guanine nucleotide-binding proteins ( $\mathrm{G}$ proteins) are ubiquitously expressed proteins that play a key role in multiple signal transduction pathways. The $\alpha$ subunit of the stimulatory $\mathrm{G}$ protein gene (GNAS) is a complex imprinted gene that generates multiple gene products through the use of multiple promoters and the first exons that splice onto a common set of downstream exons. The major GNAS gene product, which is generated by the most downstream promoter, is the ubiquitously expressed $\mathrm{G}$ protein $\alpha$-subunit (Gas). This subunit is responsible for coupling numerous hormonal and other seven-transmembrane receptors to adenylyl cyclase, and is required for receptor-stimulated intracellular cyclic adenosine monophosphate (cAMP) production (Weinstein et al., 2001, 2004). Human Gas is encoded by the GNAS1 gene, which is located on chromosome 20q13 (Kozasa et al., 1988; Schwindinger et al., 1997).

Somatically acquired, activating mutations of GNAS have been identified in the adrenal hyperplasia, ovarian cysts, thyroid carcinomas, adrenocortical, pituitary, kidney, and leydig cell tumors (Landis et al., 1989; Fragoso et al., 1998; Hayward et al., 2001; Kalfa et al., 2006; Palos-Paz et al., 2008; Taboada et al., 2009; Oczkowicz, 2012). Furthermore, several reports have documented the presence of thyroid, pituitary, and adrenocortical tumors in patients that have McCune-Albright syndrome, which is a mosaic disease caused by the sporadic, postzygotic, activating mutations of GNAS (Happle, 1986; Kirk et al., 1999; Collins et al., 2003; Weinstein et al., 2004). Collectively, these data indicate that activating mutations of GNAS may modify cell growth and might be oncogenic; however, how GNAS functions as an oncogene remains unclear (Wilson et al., 2010). To our knowledge, there has been limited research about GNAS in porcine, and its expression pattern. The current study was designed to increase the available genetic information for the porcine GNAS gene, and to evaluate whether this gene could serve as a new candidate gene for growth or apoptosis in pigs.

\section{MATERIAL AND METHODS}

\section{Animals and tissue samples}

The Jinhua pigs were bought from Jiahua pig breeding company in Jinhua, Zhejiang province. Experiments were performed according to the Regulations for the Administration of Affairs Concerning Experimental Animals (Ministry of Science and Technology, China, revised in June 2004) and approved by the Institutional Animal Care and Use Committee at Zhejiang University, Zhejiang, China. Animals were allowed access to food and water ad libitum under controlled environmental conditions and were humanely sacrificed as necessary to ameliorate suffering. A number of tissue samples of adult Jinhua pig were collected, including heart, liver, lung, kidney, thyroid gland, brain, hypothalamus, pituitary, stomach, pancreas, longissimus dorsi 
muscle, subcutaneous adipose tissue, abdominal fat, leg, large intestine, and small intestine.

Thyroid gland samples of male Jinhua pig at the age of 1, 20, 45, 60, 90, 120, and 150 days were collected. Longissimus dorsi muscle samples of different growth stages were also collected, including embryos of 60, 90, 105 days and pigs at 1, 25, 60, 90, 120, 150, 180 days after birth. All of the samples were immediately frozen in liquid nitrogen and stored at $-80^{\circ} \mathrm{C}$. Embryos of 40 days were used for Jinhua pig fibroblast cell culture.

\section{RNA isolation and cDNA synthesis}

Total RNA of all the samples was extracted using TRIzol reagent (Invitrogen, Carlsbad, CA, USA) and reverse-transcribed into cDNA using reverse transcriptase (Carlsbad) following the manufacturer protocol.

\section{GNAS cDNA cloning}

Primers for porcine GNAS cDNA cloning were designed based on the homology regions of human (GenBank accession No. NM_000547) and mouse (GenBank accession No. NM_009417). The 3' rapid amplification of cDNA ends [3'RACE (Rapid-amplification of cDNA ends); 30-Full RACE core set, TaKaRa, Dalian] was used to obtain the C-terminal coding region of the GNAS gene. The PCR was performed in a total volume of $15 \mu \mathrm{L}$ mixture, containing $10 \mathrm{x}$ PCR buffer, $50 \mathrm{ng}$ panel DNA, $0.3 \mu \mathrm{mol} / \mathrm{L}$ each primer, $250 \mu \mathrm{mol} / \mathrm{L}$ each dNTP, $2 \mathrm{mmol} / \mathrm{L} \mathrm{MgCl}_{2}$, and $1 \mathrm{U}$ Taq DNA polymerase. The PCR profile involved $3 \mathrm{~min}$ at $94^{\circ} \mathrm{C}, 35$ cycles of $30 \mathrm{~s}$ at $94^{\circ} \mathrm{C}, 30 \mathrm{~s}$ at $65^{\circ} \mathrm{C}, 30 \mathrm{~s}$ at $72^{\circ} \mathrm{C}$, and a final 5 min extension at $72^{\circ} \mathrm{C}$. The PCR products were loaded on $1.5 \%$ agarose gel for verification.

\section{Homology Analysis}

Deduced amino acid sequences of GNAS were compared to the sequences of cattle (Bos taurus, NM 181021), dog (Canis lupus familiaris, NM_001003263), human (Homo sapiens, NM_001077489), mouse (Mus musculus, NP_033401), rat (Rattus norvegicus, BC061967), xenopus (Xenopus laevis, NM_001101753), chicken (Gallus gallus, XM_417485), and zebrafish (Danio rerio, XM_001335696) by alignment with Clustal W.

\section{GNAS gene expression pattern}

The expression analysis of the GNAS gene was performed using an ABI 7500 real-time PCR thermal cycling instrument (Applied Biosystems,USA). Beta actin (GenBank accession No. AY550069) was used as an endogenous control, and a similar intensity was obtained for all samples. The specificity of PCR products were confirmed by melting curve analysis. Real-time PCR was performed in triplicate in a $20 \mu \mathrm{L}$ mixture containing $10 \mu \mathrm{L}$ SYBR Premix Ex Taq buffer (TaKaRa, Dalian, China), $0.4 \mu \mathrm{L}$ ROX Reference Dye, $0.3 \mu \mathrm{M}$ forward and reverse primers, $1 \mu \mathrm{L}$ template cDNA, and $8 \mu \mathrm{L} \mathrm{ddH}_{2} \mathrm{O}$.

The cycling conditions involved an initial $10 \mathrm{~s}$ at $95^{\circ} \mathrm{C}$, followed by 40 cycles of 2-temperature cycling, $5 \mathrm{~s}$ at $95^{\circ} \mathrm{C}$ (for denaturation) and $34 \mathrm{~s}$ at $60^{\circ} \mathrm{C}$ (for annealing and polymerization). The expression level was calculated by the $2^{-\Delta \Delta \mathrm{Ct}}$ method. All samples were 
analyzed in 2 independent runs, and the PCR products were loaded on 1.5\% agarose gel for verification. Primers used for real-time RT-PCR are presented in Table 1.

\begin{tabular}{|c|c|c|c|}
\hline \multicolumn{2}{|c|}{ Primers name } & \multirow{2}{*}{$\begin{array}{l}\text { Forward primer } \\
\text { CATGGGCTG TCTCGGAA }\end{array}$} & \multirow{2}{*}{$\begin{array}{l}\text { Reverse primer } \\
\text { AAATTTAGAGGTTCCCTTCTTAG }\end{array}$} \\
\hline GNAS & CDS & & \\
\hline & & GCTCTAAGAAGGGAACCTCT & TAGGCCGCCTTAAGCTT \\
\hline & real-time & ATGCACCTCCGTCAGTACG & AGCGGAAGGGTAAAGGG \\
\hline$B c l-2$ & real-time & CATGCGGCCTCTATTTGATT & CCCGTGGACTTCACTTATGG \\
\hline Fas & real-time & CCACGTGTGAACATGGAGTC & AGTGCAGGTACGGGAATGAG \\
\hline Caspase-3 & real-time & GCCATGGTGAAGAAGGAAAA & GTCCGTTCCAATCCCACAGT \\
\hline$\beta$-actin & real-time & ACTGGGACGACATGGAGAAGA & TTGGCTTTGGGGTTCAGG \\
\hline
\end{tabular}

\section{Preparation of siRNA and porcine fibroblast cells}

The cDNA sequence of the porcine GNAS gene was placed in the GenScript siRNA Target Finder (http://www.genscript.com/siRNA_target_finder.html) to find siRNAs (small interfering RNAs). The ability of porcine fetal fibroblasts to produce RNAi was tested in transiently transfected fibroblast cells. Porcine fibroblast cells were isolated from 40 day old fetuses, and were grown in Dulbecco's modified Eagle's minimal essential medium (DMEM, Gibco, Grand Island, USA) supplemented with $15 \%$ fetal bovine serum (FBS) at $37^{\circ} \mathrm{C}$ and $5 \%$ carbon dioxide. Twenty-four hours before transfection, $2.5 \times 10^{5}$ cells were seeded in each well of a 24-well plate (Costar, NY, USA), and cultured in growth medium without antibiotics to achieve greater than $90 \%$ confluence on the day of transfection. For transfection, 0.6 $\mu \mathrm{g}$ of each siRNA expression construct was used per well containing cells. Lipofectamine 2000 Reagent (Invitrogen) was used as the transfection reagent at a ratio of $1 \mu \mathrm{g}$ DNA: 1.5 $\mu \mathrm{L}$ lipofectamine following manufacturer protocols. The lipofectamine/DNA complexes were removed after $6 \mathrm{~h}$, and fresh medium was added to the cells. Transfection cells were harvested after $48 \mathrm{~h}$ to isolate RNA for RT-PCR (Stewart et al., 2008).

\section{Statistical analysis}

The expression level was calculated by the $2^{-\Delta \Delta \mathrm{Ct}}$ method to compare the relative expression. The Duncan's multiple comparison was conducted to analyze the expression data, and the significant level was 0.05 .

\section{RESULTS}

\section{GNAS cDNA cloning and homology analysis}

The PCR product of the porcine GNAS gene was loaded on $1.5 \%$ agarose gel for verification (Figure 1A). After sequence assembly in DNAMAN, the GNAS sequences of $1385 \mathrm{bp}$ were deposited in GenBank (accession No. GU126691). The deduced amino acid sequence shared $94.16,93.32,92.44,91.79,91.37,77.21,76.48$, and $71.93 \%$ identity with cattle, dog, human, mouse, rat, xenopus, chicken, and zebrafish, respectively. This result shows that GNAS is conserved among these species (Figure 1B). 


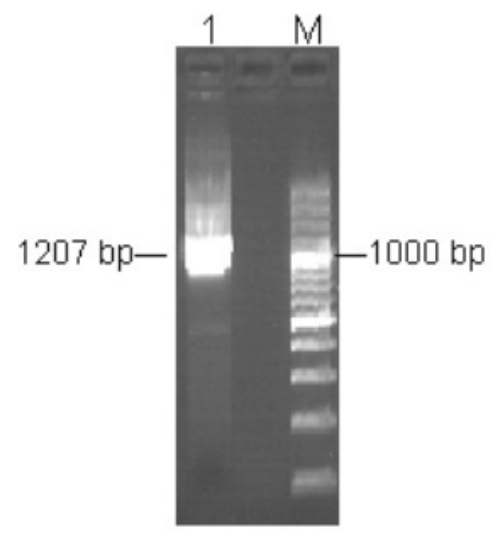

A

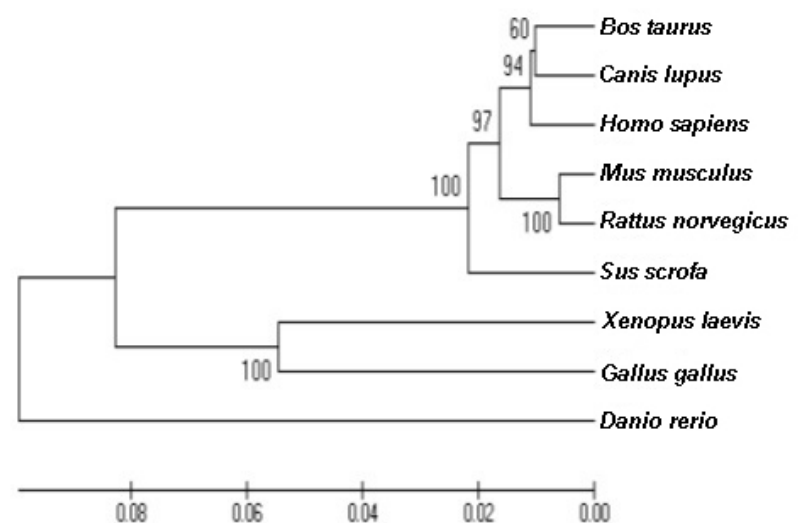

B

Figure 1. GNAS cDNA cloning and homology analysis. A. Amplifying result of porcine $G N A S$ gene. B. Evolutionary relationship of the GNAS among other species. The deduced amino acid sequence shared 94.16, 93.32, 92.44, $91.79,91.37,77.21,76.48$ and $71.93 \%$ identity with cattle, dog, human, mouse, rat, xenopus, chicken, and zebrafish respectively showing that GNAS is conserved among these species. Lane $M=100$-bp plus DNA ladder; lane $1=$ GNAS cDNA.

\section{Tissue expression pattern and developmental pattern of GNAS mRNA}

Figure 2A shows that GNAS was expressed in all of the tissues. The greatest expression was recorded in the longissimus dorsi muscle, followed by the pituitary and thyroid gland. Very low expression was recorded in the pancreas, large intestine, and small intestine. Intermediate expression was recorded in the hypothalamus, leg, and kidney.

The expression level was rather low at day 1 , it then rose at day 20 , and dropped at day 45 , and remained low in all subsequent stages (Figure 2B). However, no significant difference was recorded among the 7 stages $(\mathrm{P}>0.05)$. Therefore, GNAS gene expression was relatively stable in thyroid during the entire growth and development process.

The developmental pattern of GNAS mRNA in the longissimus dorsi muscle showed significant differences among the various developmental stages $(\mathrm{P}<0.01)$, as shown in Figure 2C. Porcine GNAS mRNA in the longissimus dorsi muscle was strongly expressed at 60 days, 90 days, and 150 days after birth. However, expression was very low during the embryo stages, particularly at -105 days, 1 day, and 180 days.

\section{Relative expression ratio of Bcl-2, Fas, Caspase-3, and GNAS between transfected and non-transfected cells}

The designed sequences of siRNA: 5'-GAUCACCCACCAUAGGGCCUGAUUA3' (sense); 5'-UAAUCAGGCCCUAUGGUGGGUGAUC-3' (antisense) were used here. The siRNA was effective at knocking down GNAS expression in cells, because its expression level was $77 \%$ downregulated. The expression of Bcl-2, Fas, and Caspase- 3 in transfected cells de- 
creased, with levels of $0.54,0.82$, and 0.79 being recorded compared to 1.00 in untransfected cells (Figure 3). The mRNA level of untransfected cells was defined as 1.00; hence, the relative expression level was easier to observe when compared to transfected cells.
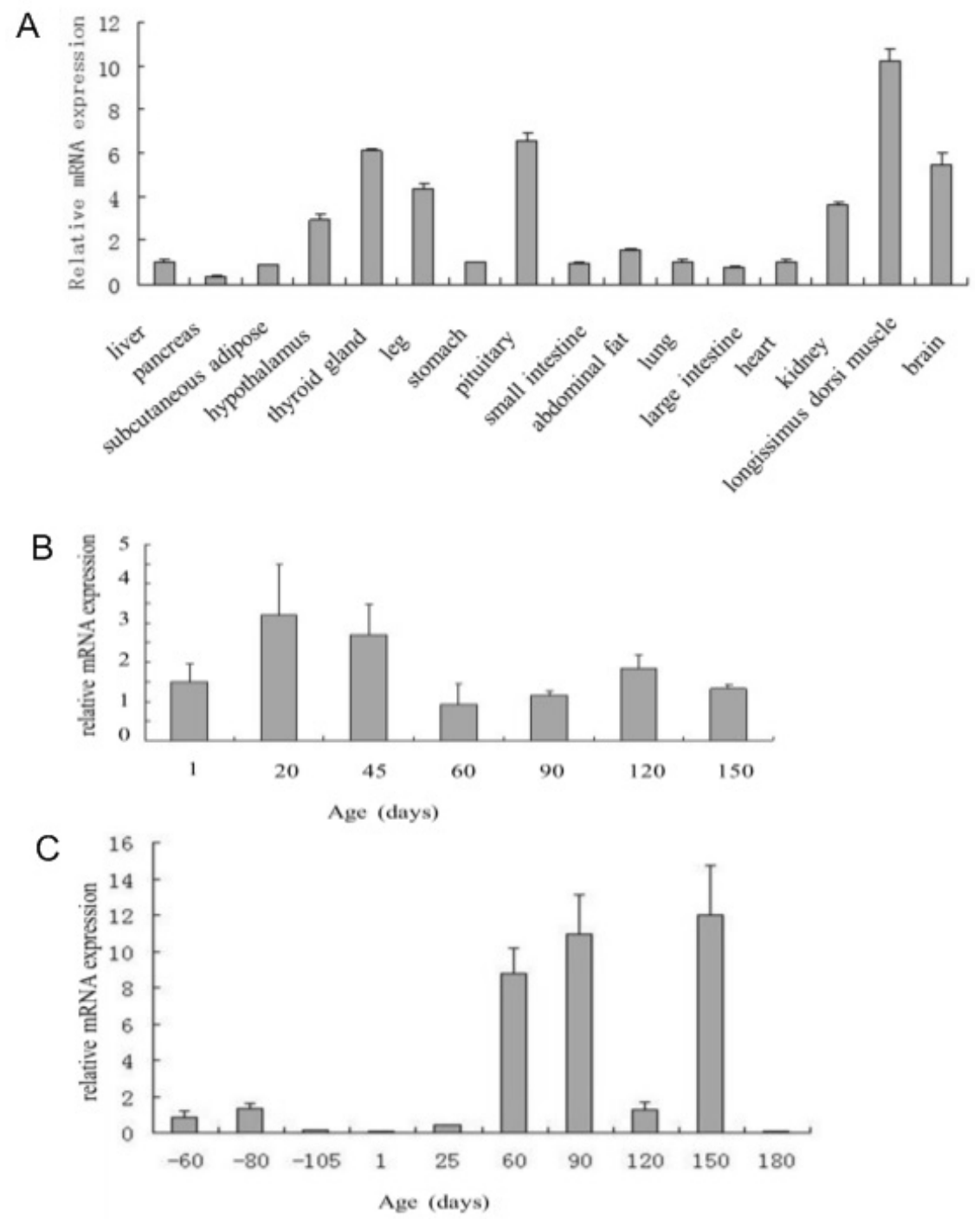

Figure 2. Tissue expression pattern and developmental pattern of GNAS mRNA of Jinhua pigs. A. GNAS gene mRNA expression pattern in different tissues. GNAS mRNA was observed in all the tissues. Longissimus dorsi muscle has the highest expression level, then pituitary, and thyroid gland. B. Developmental patterns of GNAS mRNA in thyroid gland. The expression of GNAS gene was relatively stable in thyroid during all the growth and development process $(\mathrm{P}>0.05)$. C. Developmental patterns of GNAS mRNA in longissimus dorsi muscle. Developmental pattern of GNAS mRNA in longissimus dorsi muscle showed significant difference between different developmental stages $(\mathrm{P}<0.01)$. Porcine GNAS mRNA in longissimus dorsi muscle was strongly expressed at 150 days, 90 days and 60 days. The expression level was very low during all the embryo stages. 

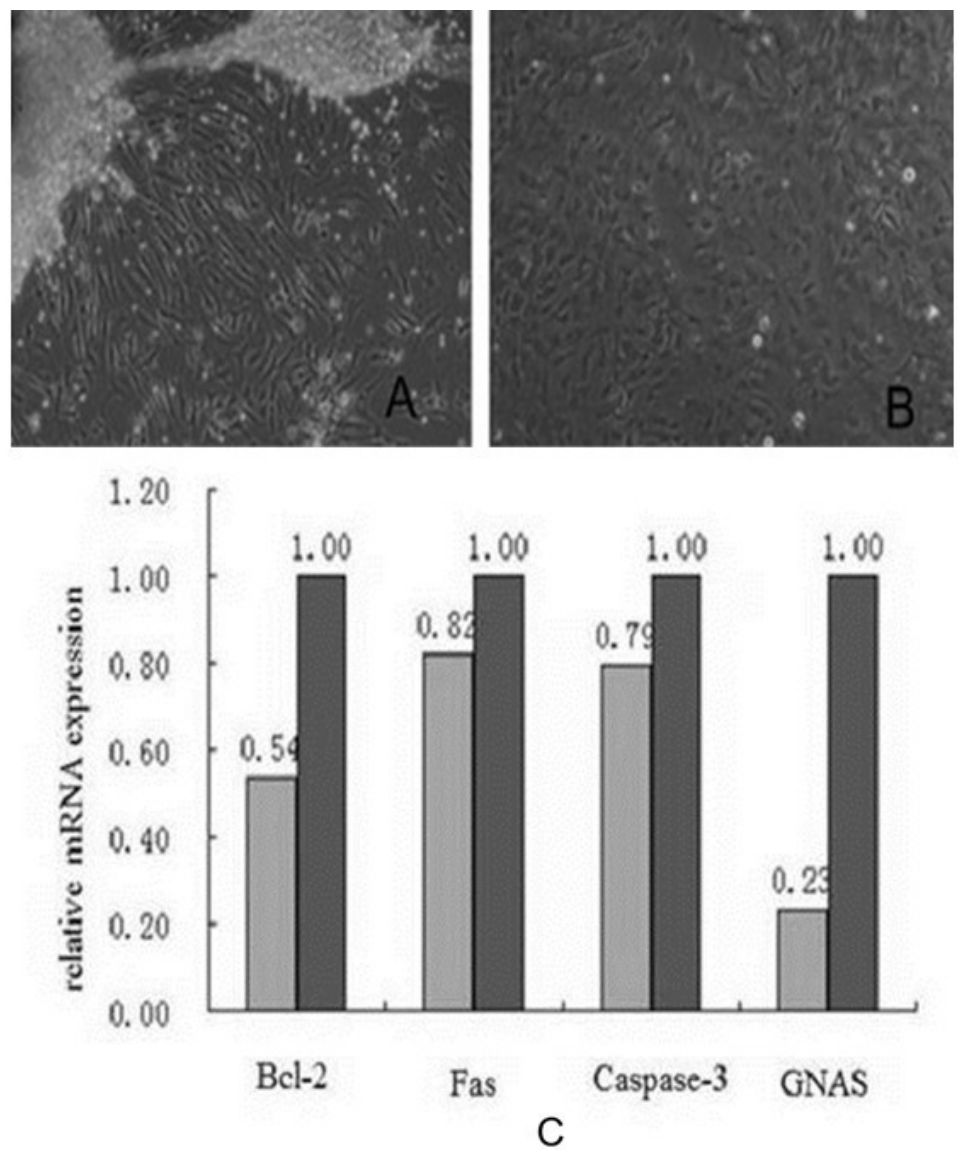

Figure 3. A. Primary porcine fibroblast cells. B. Second generation porcine fibroblast cells used for transfection. C. Relative expression ratio of Bcl-2, Fas, Caspase-3, and GNAS between transfected (left) and non-transfected (right) cells. The expression of Bcl-2, Faz, and Caspase-3 in transfected cells were all decreased with the level of 0.54, 0.82 , and 0.79 compared to 1.00 in untransfected cells. Bcl-2 $=\mathrm{B}$ cell lymphoma/leukemia-2; Fas = Fas antigen; Caspase-3 = Interleukin 1b-converting enzyme-like proteases-3; GNAS $=\alpha$ subunit of the stimulatory guanine nucleotide-binding protein gene. The mRNA level was defined as 1.00 in each untransfected cells, so relative expression level was easily to see when compared to transfected cells.

\section{DISCUSSION}

The major product of the GNAS gene is $\alpha$-subunit of the G protein. G proteins are ubiquitously expressed proteins that localize on the inside of the cell membrane, and are coupled to G-protein-coupled receptors. These proteins play a key role in multiple signal transduction pathways. The activation of G-protein-coupled receptors results in the activation of Gas, which promotes adenylyl cyclase to produce the second messenger, cAMP (Weinstein et al., 2001; Chen et al., 2004). Other GNAS gene products include NESP 55 (neuroendocrine secretory protein 55), which is a chromogranin-like protein expressed exclusively from the maternal allele and XLas (Extra Large as-like protein), which is a Gas isoform that is exclu- 
sively expressed from the paternal allele. Both proteins are primarily expressed in neuroendocrine tissues, with little being known about their biological function (Kehlenbach et al., 1994; Pasolli et al., 2000; Weiss et al., 2000; Ball et al., 2001).

In different tumor entities, such as ovarian cancer cells, lymphoma cell lines, and leukemic cells, it has been demonstrated that an increase in the concentration of the intracellular second messenger, cAMP, promotes apoptosis (Krumins and Barber, 1997; Oldham and Hamm, 2008; Eisenhardt et al., 2011). However, cAMP has been shown to have opposing effects on cell growth; for instance, cAMP either inhibits or stimulates ERK1/2 MAPK-mediated cell proliferation and/ or differentiation in a cell-type-specific manner (Stork and Schmitt, 2002; Wilson et al., 2010). In recent years, gene mutations involved in the cAMP-mediated cascade have been identified as cause of endocrine neoplasia (Mantovani et al., 2010). These gene mutations result either in the constitutive activation of cAMP formation or in increased cAMP signaling. In particular, mutations of the $\alpha$ subunit of the stimulatory G protein gene (GNAS), which lead to the constitutive activation of adenylyl cyclase (the so-called gsp oncogene), have been found in a significant proportion of GH-secreting pituitary adenomas, and in small subsets of other endocrine tumors (Williamson et al., 1995; Mantovani et al., 2010). Heterozygous null Gas mutations lead to Albright hereditary osteodystrophy, which is a syndrome characterized by obesity, in addition to other skeletal and neurological abnormalities (Patten et al., 1990; Schwindinger and Levine, 1997).

New insights about the function of the GNAS might be provided by the analysis of the expression of this gene in various tissues and developmental stages. To our knowledge, experiments confirming the expression pattern of GNAS in pigs have not been previously performed. In our study, GNAS mRNA was detected in a wide range of porcine tissues. This result proved that GNAS is a ubiquitously expressed gene. GNAS mRNA was shown to be most abundant in muscle. Detailed analysis of the porcine muscle collected at different developmental stages demonstrated that the expression level was very low during the embryo stages compared to those after birth. In particular, GNAS was strongly expressed at 150 days, 90 days, and 60 days after birth. It seems that GNAS mRNA expression is associated with porcine growth and development. Recently, a number of studies have demonstrated that genetic perturbations within the GNAS domain may result in physiological dysfunction, such as reduced body size, hypermetabolism, obesity, mental retardation, or neonatal lethality. In bovine, SNP genotype-phenotype association analyses indicate that the single intronic GNAS SNP is associated with a range of performance traits, including culled cow carcass weight and progeny carcass conformation, in addition to measures of animal body size. Such findings support the major functional role for the GNAS domain in regulating mammalian growth and maturation (Bastepe, 2008; Krechowec and Plagge, 2008; Plagge et al., 2008; Kelsey, 2009). Hence, our results were mostly consistent with these findings. We also detected the developmental patterns of GNAS mRNA in the thyroid gland of Jinhua pigs. Our results show that GNAS gene expression was relatively stable during the entire growth and development process.

RNA interference is a recent gene silencing technique that might prove to be extremely valuable for studying gene function, treating diseases, and developing novel animal models for human diseases. The ability to obtain potent and stable RNAi silencing is critical for a number of applications, especially for gene knockdown in transgenic animals (Dorsett and Tuschl, 2004). The pig (Sus scrofa) occupies a unique position amongst mammalian species, as a model organism of biomedical importance and commercial value worldwide. Pig and human genome sequences are highly conserved, making the pig an important model for the study 
of human health, and particularly for understanding complex traits (Hart et al., 2007). To our knowledge, there has been limited research about GNAS in farm animals, especially in pigs.

To examine the role of GNAS in apoptosis in porcine, the mRNA expression of 3 apoptosis related markers (Bcl-2, Fas, and Caspase-3) was evaluated using the RNAi of GNAS in porcine fibroblasts cells. Bcl-2 and related cytoplasmic proteins are key regulators of apoptosis, which is the cell suicide program that is critical for development, tissue homeostasis, and protection against pathogens (Adams and Cory, 1998). Caspases are a class of proteases that are instrumental for carrying out many cellular functions, including differentiation, remodeling, and death. Among the executioner caspases, the activation of Caspase- 3 plays an extremely important role in apoptosis and is considered to be the terminal event preceding cell death (Hengartner, 2000; Kumar, 2007; Snigdha et al., 2012). A subset of tumor necrosis factor receptor (TNFR) family members is involved in initiating the cell death signaling cascade; hence, it is referred to as the 'death receptor family'. A very potent member of the death receptor family is Fas, which, upon binding its Fas-ligand (FasL), efficiently induces apoptosis (Reichmann, 2002). Our study demonstrated that the targeted disruption of GNAS in all porcine fibroblast cells leads to interference with Bcl-2, Caspase-3, and Fas mRNA expression. The expression of all the 3 genes declined to different levels after the interruption of GNAS. Yet, RT-PCR is not sufficient to precisely estimate abundance. Hence, the application of other protocols might generate conflicting results. Therefore, further studies are needed to obtain more information about the functioning of these apoptosis genes in pigs.

In conclusion, porcine GNAS full-length cDNA was cloned, with its homology being compared to other species. Furthermore, the tissue expression pattern of GNAS was analyzed for adult Jinhua pigs, in addition to the developmental patterns of GNAS mRNA in the thyroid gland and longissimus dorsi muscle. Previous studies about GNAS expression focus on different patterns of expression between healthy and sick specimens. There has been limited research about GNAS temporal expression pattern at different growth stages in livestock. As far as we know, this study presents the first examination of GNAS expression in different tissues at different ages of porcine by real-time analytical RT-PCR. The temporal expression data obtained indicate changes in the developmental expression of GNAS for the healthy pigs, which provided the normal levels of GNAS expression for use as a diagnostic reference in pigs. Furthermore, we examined the RNAi silencing of GNAS expression using transient transfected fetal fibroblasts cells, to detect the novel effect of siRNA expression leading to interference with Caspase-3, Fas and Bcl-2 mRNA expression, which are recognized as apoptosis related markers. The potential relationship between GNAS expression and apoptosis in pigs was presented in our study, which is anticipated to serve as a very useful reference for human research, with further exploration about GNAS expression being recommended.

\section{ACKNOWLEDGMENTS}

Research supported by the National Natural Science Foundation Program (\#30972078, \#31272424) and the China Postdoctoral Science Foundation Project (\#2011M501018).

\section{REFERENCES}

Adams JM and Cory S (1998). The Bcl-2 protein family: arbiters of cell survival. Science 281: 1322-1326. 
Ball ST, Williamson CM, Hayes C, Hacker T, et al. (2001). The spatial and temporal expression pattern of Nesp and its antisense Nespas, in mid-gestation mouse embryos. Mech. Dev. 100: 79-81.

Bastepe M (2008). The GNAS locus and pseudohypoparathyroidism. Adv. Exp. Med. Biol. 626: 27-40.

Chen M, Haluzik M, Wolf NJ, Lorenzo J, et al. (2004). Increased insulin sensitivity in paternal Gnas knockout mice is associated with increased lipid clearance. Endocrinology 145: 4094-4102.

Collins MT, Sarlis NJ, Merino MJ, Monroe J, et al. (2003). Thyroid carcinoma in the McCune-Albright syndrome: contributory role of activating Gs alpha mutations. J. Clin. Endocrinol. Metab. 88: 4413-4417.

Dorsett Y and Tuschl T (2004). siRNAs: applications in functional genomics and potential as therapeutics. Nat. Rev. Drug Discov. 3: 318-329.

Eisenhardt A, Scherag A, Jockel KH, Reis H, et al. (2011). Lack of association of the genotype in the GNAS Fok I polymorphism and prostate cancer. Urol. Int. 87: 80-86.

Fragoso MC, Latronico AC, Carvalho FM, Zerbini MC, et al. (1998). Activating mutation of the stimulatory G protein (gsp) as a putative cause of ovarian and testicular human stromal Leydig cell tumors. J. Clin. Endocrinol. Metab. 83: 2074-2078.

Happle R (1986). The McCune-Albright syndrome: a lethal gene surviving by mosaicism. Clin. Genet. 29: 321-324.

Hart EA, Caccamo M, Harrow JL, Humphray SJ, et al. (2007). Lessons learned from the initial sequencing of the pig genome: comparative analysis of an 8-Mb region of pig chromosome 17. Genome Biol. 8: R168.

Hayward BE, Barlier A, Korbonits M, Grossman AB, et al. (2001). Imprinting of the G(s)alpha gene GNAS1 in the pathogenesis of acromegaly. J. Clin. Invest. 107: R31-R36.

Hengartner MO (2000). The biochemistry of apoptosis. Nature 407: 770-776.

Kalfa N, Lumbroso S, Boulle N, Guiter J, et al. (2006). Activating mutations of Gsalpha in kidney cancer. J. Urol. 176: 891-895.

Kehlenbach RH, Matthey J and Huttner WB (1994). XL alpha s is a new type of G protein. Nature 372: 804-809.

Kelsey G (2009). Epigenetics and imprinted genes: insights from the imprinted Gnas locus. Horm. Res. 71 (Suppl 2): $22-29$.

Kirk JM, Brain CE, Carson DJ, Hyde JC, et al. (1999). Cushing's syndrome caused by nodular adrenal hyperplasia in children with McCune-Albright syndrome. J. Pediatr. 134: 789-792.

Kozasa T, Itoh H, Tsukamoto T and Kaziro Y (1988). Isolation and characterization of the human Gs alpha gene. Proc. Natl. Acad. Sci. U. S. A. 85: 2081-2085.

Krechowec S and Plagge A (2008). Physiological dysfunctions associated with mutations of the imprinted Gnas locus. Physiology 23: 221-229.

Krumins AM and Barber R (1997). Examination of the effects of increasing Gs protein on beta2-adrenergic receptor, Gs, and adenylyl cyclase interactions. Biochem. Pharmacol. 54: 61-72.

Kumar S (2007). Caspase function in programmed cell death. Cell Death. Differ. 14: 32-43.

Landis CA, Masters SB, Spada A, Pace AM, et al. (1989). GTPase inhibiting mutations activate the alpha chain of Gs and stimulate adenylyl cyclase in human pituitary tumours. Nature 340: 692-696.

Mantovani G, Lania AG and Spada A (2010). GNAS imprinting and pituitary tumors. Mol. Cell Endocrinol. 326: 15-18.

Oczkowicz M, Piestrzynska-Kajtoch A, Ropka-Molik K, Rejduch B, et al. (2012). Expression and imprinting analysis of the NESP55 gene in pigs. Gene Expr. Patterns. 12: 18-23.

Oldham WM and Hamm HE (2008). Heterotrimeric G protein activation by G-protein-coupled receptors. Nat. Rev. Mol. Cell Biol. 9: 60-71.

Palos-Paz F, Perez-Guerra O, Cameselle-Teijeiro J, Rueda-Chimeno C, et al. (2008). Prevalence of mutations in TSHR, GNAS, PRKAR1A and RAS genes in a large series of toxic thyroid adenomas from Galicia, an iodine-deficient area in NW Spain. Eur. J. Endocrinol. 159: 623-631.

Pasolli HA, Klemke M, Kehlenbach RH, Wang Y, et al. (2000). Characterization of the extra-large G protein alpha-subunit XLalphas. I. Tissue distribution and subcellular localization. J. Biol. Chem. 275: 33622-33632.

Patten JL, Johns DR, Valle D, Eil C, et al. (1990). Mutation in the gene encoding the stimulatory G protein of adenylate cyclase in Albright's hereditary osteodystrophy. N. Engl. J. Med. 322: 1412-1419.

Plagge A, Kelsey G and Germain-Lee EL (2008). Physiological functions of the imprinted Gnas locus and its protein variants Galpha(s) and XLalpha(s) in human and mouse. J. Endocrinol. 196: 193-214.

Reichmann E (2002). The biological role of the Fas/FasL system during tumor formation and progression. Semin. Cancer Biol. 12: 309-315.

Schwindinger WF, Reese KJ, Lawler AM, Gearhart JD, et al. (1997). Targeted disruption of Gnas in embryonic stem cells. Endocrinology 138: 4058-4063.

Snigdha S, Smith ED, Prieto GA and Cotman CW (2012). Caspase-3 activation as a bifurcation point between plasticity and cell death. Neurosci. Bull. 28: 14-24. 
Stewart CK, Li J and Golovan SP (2008). Adverse effects induced by short hairpin RNA expression in porcine fetal fibroblasts. Biochem. Biophys. Res. Commun. 370: 113-117.

Stork PJ and Schmitt JM (2002). Crosstalk between cAMP and MAP kinase signaling in the regulation of cell proliferation. Trends Cell Biol. 12: 258-266.

Taboada GF, Tabet AL, Naves LA, de Carvalho DP, et al. (2009). Prevalence of gsp oncogene in somatotropinomas and clinically non-functioning pituitary adenomas: our experience. Pituitary 12: 165-169.

Weinstein LS, Yu S, Warner DR and Liu J (2001). Endocrine manifestations of stimulatory G protein alpha-subunit mutations and the role of genomic imprinting. Endocr. Rev. 22: 675-705.

Weinstein LS, Liu J, Sakamoto A, Xie T, et al. (2004). Minireview: GNAS: normal and abnormal functions. Endocrinology 145: 5459-5464.

Weiss U, Ischia R, Eder S, Lovisetti-Scamihorn P, et al. (2000). Neuroendocrine secretory protein 55 (NESP55): alternative splicing onto transcripts of the GNAS gene and posttranslational processing of a maternally expressed protein. Neuroendocrinology 71: 177-186.

Williamson EA, Ince PG, Harrison D, Kendall-Taylor P, et al. (1995). G-protein mutations in human pituitary adrenocorticotrophic hormone-secreting adenomas. Eur. J. Clin. Invest. 25: 128-131.

Wilson CH, McIntyre RE, Arends MJ and Adams DJ (2010). The activating mutation R201C in GNAS promotes intestinal tumourigenesis in Apc(Min/+) mice through activation of Wnt and ERK1/2 MAPK pathways. Oncogene 29: 4567-4575. 